\title{
Mapeamento de competências em bibliotecas \\ universitárias
}

\begin{tabular}{|c|c|}
\hline & 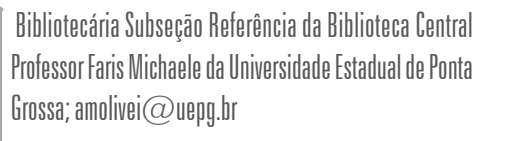 \\
\hline \multicolumn{2}{|l|}{ Eunice Silva Novais } \\
\hline & $\begin{array}{l}\text { Bibliotecária Subseçäa Empréstimo da Biblioteca Central } \\
\text { Professor Faris Nichaele da Universidadde Estadual de Ponta } \\
\text { Grossa; enouvais @ueppg.br }\end{array}$ \\
\hline \multicolumn{2}{|l|}{ lvani da Silva } \\
\hline & 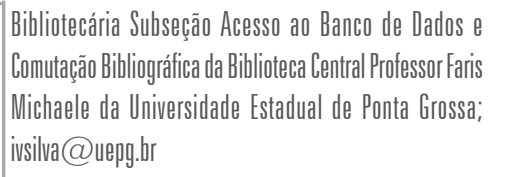 \\
\hline \multicolumn{2}{|c|}{ Maria Luiza Fernandes Bertholino } \\
\hline & $\begin{array}{l}\text { Bibliotecária Diretora da Biblioteca Central Professor Faris } \\
\text { Michaele da Universiddade Estadual de Ponta Grossa; } \\
\text { mluzia@uepg.br }\end{array}$ \\
\hline
\end{tabular}

Este estudo tem por objetivo apresentar um mapeamento de competências para identificar os conhecimentos, habilidades e atitudes existentes e necessárias ao staff da Biblioteca Central Prof. Faris Michaele da Universidade Estadual de Ponta Grossa - Paraná. Para tanto, foram listados os cargos existentes e identificadas as suas atribuições para direcionar e estabelecer diretrizes. Verificou-se que, para o segmento bibliotecário, os conhecimentos e as habilidades atingiram os pontos fortes, médios e fracos e as atitudes atingiram pontos fortes e médios. Para o auxiliar de biblioteca, os conhecimentos e habilidades atingiram pontos fortes e médios e as atitudes foram todas classificadas como pontos médios. Para o segmento técnico de biblioteca, os conhecimentos e habilidades classificaram-se entre pontos fortes e médios e todas as atitudes atingiram pontos fortes.

Palavras-chave: Gestão de competências; Competência profissional; Biblioteca Universitária. 


\section{Introdução}

Nos últimos anos, os recursos humanos ganharam um papel importante para as organizações. As competências tornam-se cada vez mais evidentes dentro deste universo gerando competição por pessoas capacitadas no mercado de trabalho. Neste ambiente, compreender e identificar as competências de seus funcionários pode trazer inúmeros benefícios para as organizações, permitindo indicar quais competências eles possuem e quais deverão buscar desenvolver ou aperfeiçoar. Assim, este estudo tem por objetivo apresentar um mapeamento de competências para identificar os conhecimentos, habilidades e atitudes existentes e necessárias ao staff da Biblioteca Central Prof. Faris Michaele, da Universidade Estadual de Ponta Grossa.

\section{Competências}

Vários autores têm tentado definir o conceito de competência. Os primeiros conceitos apareceram nos estudos de Prahalad e Hamel ( 1990 apud FLEURY, 1999) que definiram competência essencial como um conjunto de habilidades e tecnologias necessárias e que agregam valor a uma organização.

Segundo Tejada (1999, p. 3), o termo competência :

etimologicamente, vem do verbo latino competere, com o significado de aproximar-se, encontrar-se, que significa responder a, corresponder, que dá lugar ao adjetivo competens-entris como competente convincente e ao substantivo competio-onis, como sentido rival.

"As competências combinam conhecimento e habilidades; representam tanto a base dos conhecimentos tácitos quanto de habilidades, necessários para a realização de ações produtivas." (PRAHALAD, 1990 apud FLINK; VANALLE, 2003).

Para Zafirian (1996, p. 5), competência significa "assumir responsabilidades frente a situações de trabalho complexas [aliado] [...] ao exercício sistemático de uma reflexibilidade no trabalho", onde em um ambiente competitivo e mutável não é possível considerar o trabalho apenas como um conjunto de tarefas pré-definidas.

Durand (1998) afirma que o conceito de competência está baseado em três dimensões interdependentes - conhecimentos, habilidades e atitudes - englobando questões técnicas, cognição e as atitudes relacionadas ao trabalho. Conforme ilustra a FIG. I

Entretanto para alguns autores apenas ter conhecimentos ou capacidades não significa ser uma pessoa competente, é necessário saber aplicar esses conhecimentos e/ou capacidades em situações reais. Para confirmar essa assertiva, Daólio (2004) destaca:

competente é alguém que não só sabe o que fazer (know-what), mas também o como fazer (know-how) e o porquê fazer (knowwhy). Isto é, o competente consegue entregar um bom resultado 
porque possui plena confiança e consistência do que tem a fazer, que faz com 'conhecimento de causa.

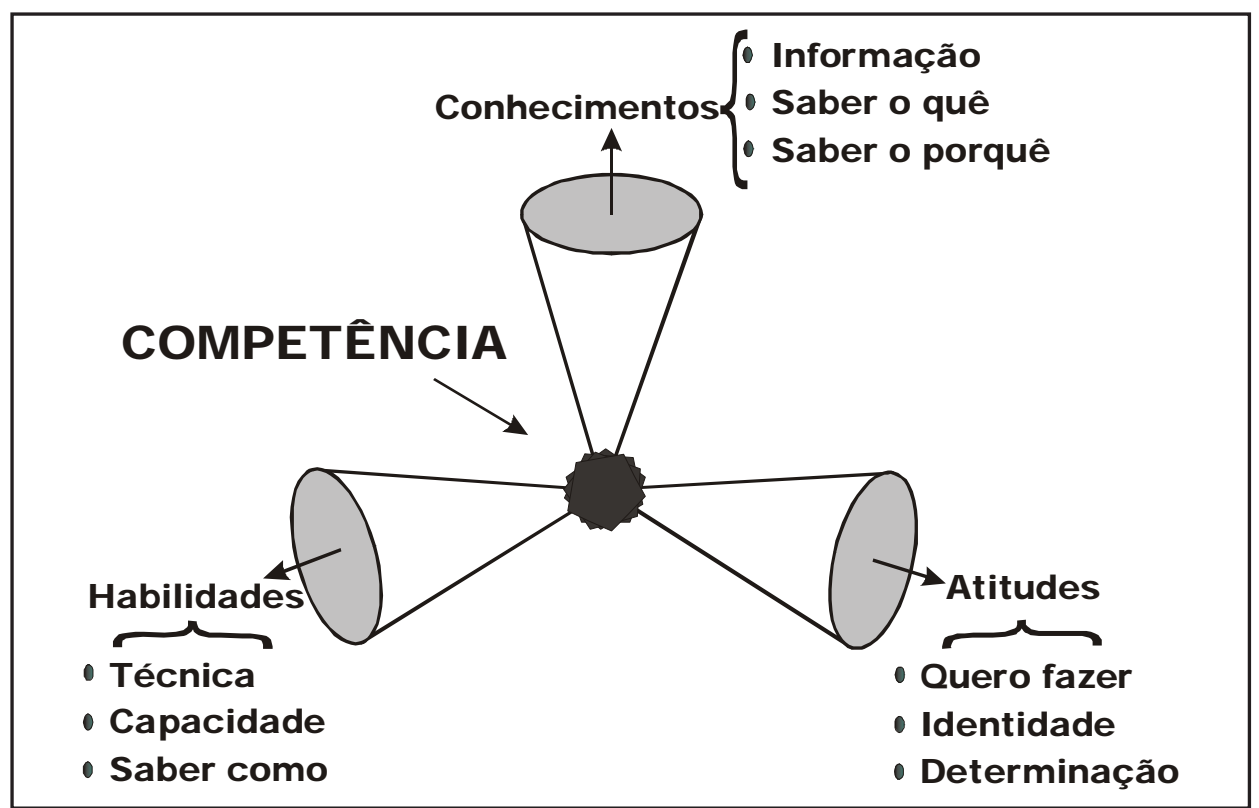

FIGURA. I - As três dimensões da competência

Fonte: Durand (2000) apud BRANDÃO; GUIMARÃES, 2001 , p. 10

Ropé e Tauguy (1997) corroboram com a citação acima, ao mencionarem que um dos principais pontos do que seja competência é que esta não pode ser entendida se estiver separada da ação. Ou seja, a pessoa precisa tomar iniciativas, ir além das tarefas pré-determinadas, saber dominar novas situações no ambiente de trabalho.

\section{Metodologia}

\section{Sujeitos}

Os sujeitos desta pesquisa constituíram-se dos: bibliotecários, auxiliares de biblioteca e técnicos de biblioteca lotados na Biblioteca Central da Universidade Estadual de Ponta Grossa.

\section{Instrumento de coleta de dados}

Como instrumento de coleta de dados utilizou-se um questionário específico para cada cargo com questões abertas e fechadas. As questões relacionadas às competências (conhecimentos, atitudes e habilidades) foram pré-selecionadas da literatura biblioteconômica, do catálogo de atribuições de cargos da Universidade Estadual de Ponta Grossa e da Classificação Brasileira de Ocupações. (CBO, 2002; UNIVERSIDADE ESTADUAL DE PONTA GROSSA, 1997). (ANEXOS A, B,C).

A análise dos dados respaldou-se na tabulação dos mesmos que descreveram respectivamente conhecimento, habilidades e atitudes do bibliotecário, auxiliar de biblioteca e técnico de biblioteca. Os conteúdos abordados nas questões fechadas constam do QUAD. I . 
As competências (conhecimentos, atitudes e habilidades) foram listadas e cada funcionário se auto-avaliou em uma escala de I a 5 (I = excelente; 2 = bom; $3=$ regular; $4=$ insuficiente; $5=$ nenhum).

QUADRO. I - Conteúdos das questões fechadas por cargos

\begin{tabular}{|c|c|c|}
\hline \multicolumn{3}{|l|}{ BIBLIOTECÁRIO } \\
\hline CONHECIMENTOS & HABILIDADES & ATITUDES \\
\hline $\begin{array}{l}47 \text { itens que } \\
\text { abrangeram os seguintes } \\
\text { conteúdos: estrutura admi- } \\
\text { nistrativa local, informática } \\
\text { básica, serviço de referência, } \\
\text { uso e implantação de } \\
\text { tecnologias da informação, } \\
\text { atividades administrativas e } \\
\text { específicas. }\end{array}$ & $\begin{array}{l}26 \text { itens distribuídos } \\
\text { em habilidades de ação e } \\
\text { capacitação /comportamento } \\
\text { que englobaram: linguagem, } \\
\text { soluções rápidas, operação de } \\
\text { recursos tecnológicos, argu- } \\
\text { mentação, planejamento, } \\
\text { políticas, padrão de qualidade, } \\
\text { relacionamento com o cliente } \\
\text { e demonstração de capacitação } \\
\text { para o trabalho. }\end{array}$ & $\begin{array}{l}24 \text { itens que envol- } \\
\text { veram os temas: qualidade e } \\
\text { satisfação do cliente, ética, } \\
\text { profissionalismo e busca de } \\
\text { aperfeiçoamento profissional. }\end{array}$ \\
\hline \multicolumn{3}{|l|}{ AUXILIAR DE BIBLIOTECA } \\
\hline CONHECIMENTOS & HABILIDADES & ATITUDES \\
\hline $\begin{array}{l}\quad 34 \text { itens que } \\
\text { abrangeram os seguintes } \\
\text { conteúdos: estrutura admi- } \\
\text { nistrativa local, serviço de } \\
\text { referência, uso e implantação } \\
\text { de tecnologias da infor- } \\
\text { mação, empréstimo, } \\
\text { aquisição, preservação, } \\
\text { processos técnicos e } \\
\text { atividades administrativas. }\end{array}$ & $\begin{array}{l}\qquad 7 \text { itens distribuídos } \\
\text { em habilidades de ação e } \\
\text { capacitação / comportamento, } \\
\text { que englobaram: clientes, } \\
\text { linguagem, novas tecnologias, } \\
\text { argumentação, resolução de } \\
\text { problemas e adaptação, } \\
\text { relacionamento, comunicação } \\
\text { e demonstrações de } \\
\text { capacidade relacionadas a } \\
\text { stress, proatividade, equipe e } \\
\text { comprometimento. }\end{array}$ & 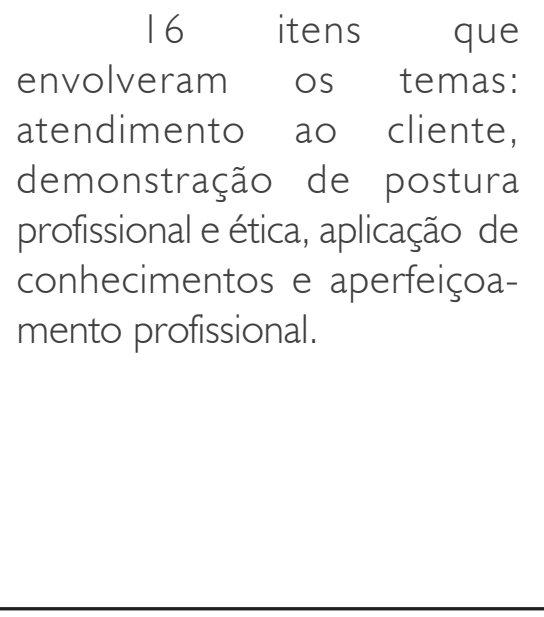 \\
\hline \multicolumn{3}{|l|}{ TÉCNICO DE BIBLIOTECA } \\
\hline CONHECIMENTOS & HABILIDADES & ATITUDES \\
\hline $\begin{array}{l}57 \text { itens que } \\
\text { abrangeram os seguintes } \\
\text { conteúdos: estrutura } \\
\text { administrativa local, serviço } \\
\text { de referência, uso e } \\
\text { implantação de tecnologias } \\
\text { da informação, empréstimo, } \\
\text { aquisição, preservação, } \\
\text { processos técnicos e } \\
\text { atividades administrativas. }\end{array}$ & $\begin{array}{l}\text { I7 itens distribuídos } \\
\text { em habilidade de ação e } \\
\text { capacitação / comportamento. } \\
\text { clientes, linguagem, novas } \\
\text { tecnologias, argumentação, } \\
\text { resolução de problemas e } \\
\text { adaptação, comportamento } \\
\text { relacionamento, comunicação } \\
\text { e demonstrações de } \\
\text { capacidade relacionadas à } \\
\text { stress, proatividade, equipe e } \\
\text { comprometimento. }\end{array}$ & $\begin{array}{l}\text { I6 itens que } \\
\text { envolveram os temas: } \\
\text { atendimento ao cliente e } \\
\text { demonstração de postura } \\
\text { profissional ética, aplicação de } \\
\text { conhecimentos e aperfei- } \\
\text { çoamento profissional. }\end{array}$ \\
\hline
\end{tabular}




\section{Procedimentos}

A coleta de dados envolveu a distribuição dos questionários para cada segmento (Bibliotecário, Auxiliar de Biblioteca e Técnico de Biblioteca), acompanhados por uma carta de apresentação, enfatizando os objetivos da pesquisa. Os questionários foram entregues pessoalmente aos segmentos dos sujeitos investigados.

\section{Análise dos dados}

Os dados foram tabulados, transcritos para planilhas e, após, foram estabelecidos os pontos fortes, médios e fracos de cada item, conforme QUAD. 2. Uma vez distribuídos para cada pontuação, os itens foram separados pelas áreas de atuação e computada a média para cada uma para elaboração dos gráficos e interpretação dos dados.

QUADRO. 2 - Pontos e seus respectivos graus de atribuição

\begin{tabular}{|l|l|}
\hline \multicolumn{1}{|c|}{ Pontos } & \multicolumn{1}{c|}{ Graus recebidos } \\
\hline Forte & Excelente e bom \\
\hline Médio & Excelente, bom, regular, insuficiente e nenhum \\
\hline Fraco & Insuficiente e nenhum \\
\hline
\end{tabular}

Fonte: Dados da pesquisa

\section{Caracterização dos sujeitos}

Dos 39 questionários enviados, retornaram 23, representando 58,97\% da população alvo, conforme QUAD. 3.

QUADRO. 3 - Questionários enviados

\begin{tabular}{|l|c|c|c|}
\hline \multicolumn{1}{|c|}{ Segmentos } & Questionários enviados $(\mathrm{n})$ & Questionários devolvidos $(\mathrm{n})$ & $\%$ \\
\hline Bibliotecário & 9 & 7 & $77,77 \%$ \\
\hline Auxiliar de biblioteca & 25 & 12 & $48 \%$ \\
\hline Técnico de biblioteca & 5 & 4 & $80 \%$ \\
\hline Total & 39 & 23 & $58,97 \%$ \\
\hline
\end{tabular}

Fonte: Dados da pesquisa

O universo de sujeitos pesquisado foi de 23 elementos: 7 Bibliotecários, 12 Auxiliares de Biblioteca e 4 Técnicos de Biblioteca.

TABELA I - Caracterização da população do Estudo segundo variáveis sexo e idade

\begin{tabular}{|c|c|c|c|c|c|c|c|c|c|c|c|c|c|}
\hline \multirow{3}{*}{ Cargo } & \multicolumn{4}{|c|}{ Sexo } & \multicolumn{8}{|c|}{ Idade } & \multirow{3}{*}{ Total } \\
\hline & \multicolumn{2}{|c|}{ Feminino } & \multicolumn{2}{|c|}{ Masculino } & \multicolumn{2}{|c|}{18 a 25} & \multicolumn{2}{|c|}{26 a 35} & \multicolumn{2}{|c|}{36 a 45} & \multicolumn{2}{|c|}{45 a 55} & \\
\hline & $f$ & $\%$ & $\mathrm{f}$ & $\%$ & $f$ & $\%$ & f & $\%$ & $f$ & $\%$ & $f$ & $\%$ & \\
\hline Auxiliar biblioteca. & 9 & 75 & 3 & 25 & 2 & 16,6 & I & 8,3 & 8 & 66,6 & 1 & 8,3 & 12 \\
\hline Bibliotecário & 7 & 100 & - & - & - & - & 3 & 43 & 4 & 57 & - & - & 7 \\
\hline Técnico biblioteca & 3 & 75 & 1 & 25 & - & - & - & - & 3 & 75 & 1 & 25 & 4 \\
\hline Total & 19 & & 4 & & 2 & & 4 & & 15 & & 2 & & 23 \\
\hline
\end{tabular}


O staff da Biblioteca é composto, na maioria dos cargos, por sujeitos do sexo feminino, com faixa etária que varia de 18 a 55 anos, predominando a faixa etária de 36 a 45 anos.

TABELA 2 - Caracterização da população do Estudo segundo a variável grau de instrução

\begin{tabular}{|c|c|c|c|c|c|c|c|}
\hline \multirow{2}{*}{ Formação } & \multicolumn{2}{|c|}{ Auxiliar de biblioteca } & \multicolumn{2}{|c|}{ Bibliotecário } & \multicolumn{2}{|c|}{ Técnico de biblioteca } & \multirow{2}{*}{ Total } \\
\hline & f & $\%$ & f & $\%$ & $f$ & $\%$ & \\
\hline 10. Grau & | & 8,3 & - & - & - & - & | \\
\hline 20.Grau & 4 & 33,3 & - & - & I & 25 & 5 \\
\hline 30. Grau Incompleto & 4 & 33,3 & - & - & - & - & 4 \\
\hline 30. Grau & 2 & 16,6 & - & - & - & - & 2 \\
\hline Especialista & 1 & 8,3 & 2 & 28,6 & 1 & 25 & 4 \\
\hline Mestre & & & 5 & 71,4 & 2 & 50 & 7 \\
\hline Total & 12 & & 7 & & 4 & & 23 \\
\hline
\end{tabular}

Fonte: Dados da pesquisa

O status de qualificação da equipe da Biblioteca, conforme TAB. 2, mostrou-se variado.

Quanto à titulação, o cargo de auxiliar de biblioteca possui sujeitos com a formação de primeiro grau ao título de especialista, possuindo a maioria, em percentuais proporcionais, segundo grau completo e terceiro grau incompleto. A categoria bibliotecário aparece com 7l,4\% com mestrados concluídos. $O$ cargo de técnico de biblioteca abrangeu de segundo grau à titulação de mestre, cuja última categoria abrange 50\% dos respondentes.

\section{Conhecimentos, Habilidades e Atitudes}

\section{Bibliotecários}

\section{Conhecimentos}

A análise dos dados dos conhecimentos do bibliotecário baseou-se em 47 itens listados, conforme dados do QUAD. I.

De acordo com os graus atribuídos para os itens que avaliaram os conhecimentos do Bibliotecário, a maioria atingiu a classificação intermediária, desde o grau excelente até o nenhum.

Os conhecimentos com pontos fortes (grau excelente e bom) foram indicados em duas áreas: estrutura administrativa local com grau excelente (43\%) e bom (50\%); e serviço de referência, com grau excelente (43\%) e bom (57\%), cujos percentuais não variaram de forma significativa.

O domínio da estrutura administrativa local abrangeu o conhecimento sobre estrutura, funcionamento, missão, políticas, objetivos, produtos e serviços da Biblioteca e no serviço de referência o uso das bases de dados do acervo da Biblioteca, ou seja, o uso do sistema local de busca, atividade esta presente no dia-a-dia de trabalho.

Para conhecimentos classificados dentre os pontos médios, encontramse os que abrangem informática, a maioria dos serviços de referência, o uso de novas tecnologias (nov. tec.), atividades administrativas (atv. adm.) e as atividades que envolvem o conhecimento específico da área de biblioteconomia (atv. con. esp.). (GRÁF. I). 


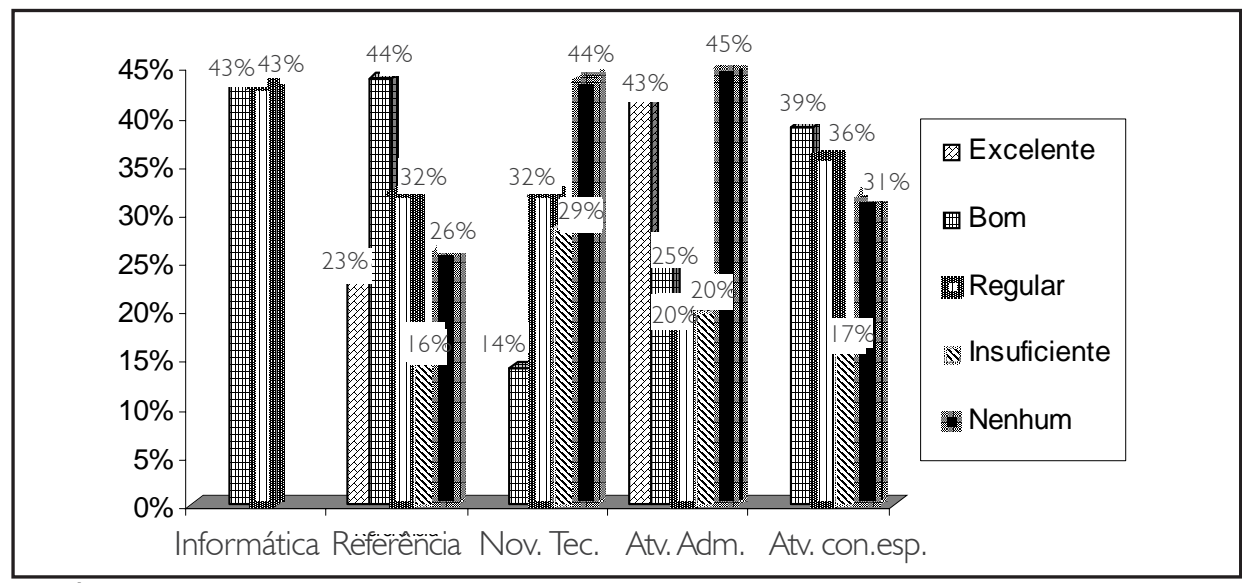

GRÁFICO I - Conhecimentos dos Bibliotecários - Pontos médios

Fonte: Dados da pesquisa

Os conhecimentos de informática envolveram softwares da Microsoft Office e internet e apresentam índices de conhecimento proporcionais. Os serviços de referência, em graus variados de conhecimento, enquadram-se, na maioria, nos graus bom e regular, porém há ainda serviços com grau insuficiente.

Os conhecimentos que atingiram pontos fracos (GRAF. 2) envolveram atividades do serviço de referência (clipping de informação e biblioterapia); novas tecnologias (suportes, migração de dados e educação à distância); atividades administrativas (atividades relacionadas à administração de consórcios em unidades de informação) e conhecimentos específicos (estudos relacionados à cienciometria, bibliometria e infometria).

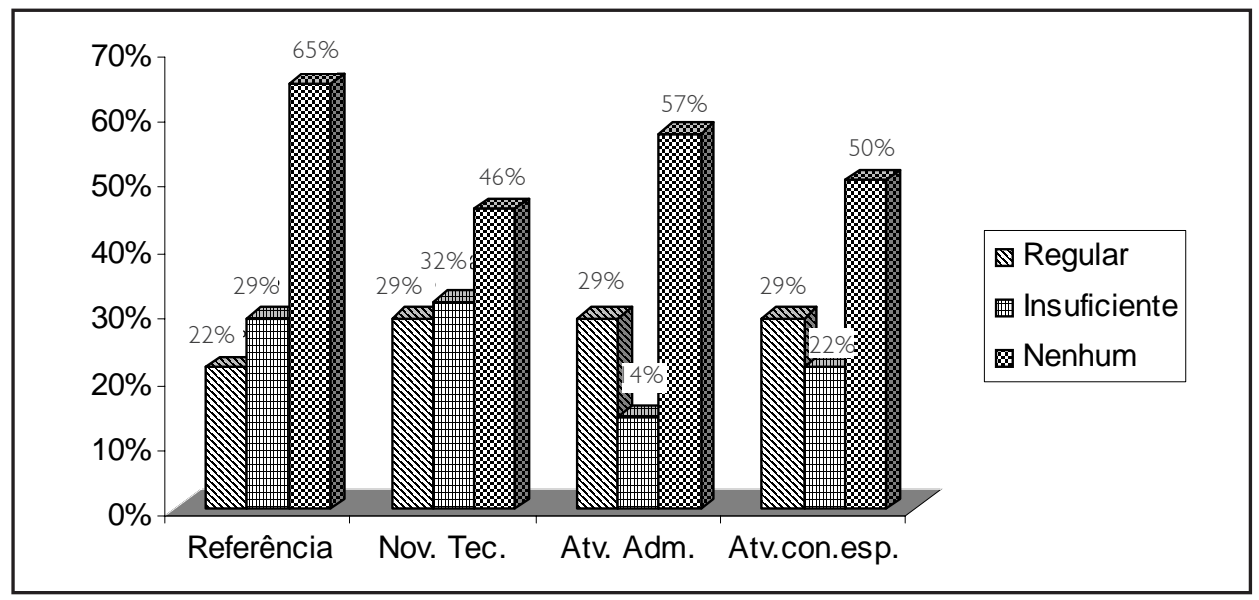

GRÁFICO 2 - Conhecimentos dos Bibliotecários - Pontos fracos Fonte: Dados da pesquisa

Pelos dados, nota-se que os pontos fracos dos bibliotecários estão relacionadas às atividades não realizadas na biblioteca em que atuam. Entretanto, diante da sociedade do conhecimento, faz-se necessário que o profissional bibliotecário mesmo que não esteja realizando determinadas atividades, deva manter-se atualizado tanto em assuntos relacionados a sua área como em áreas correlatas.

Nas observações realizadas pelos bibliotecários percebe-se que os mesmos têm se preocupado com sua atualização ao elencar os cursos e eventos que gostariam de fazer/participar para melhorar o seu desempenho no trabalho. 
São eles: Bancos de dados; Informática; Web design; Gerenciamento de pessoas; Conservação e preservação do acervo.

Considerou-se importante a elaboração de um programa de treinamento na biblioteca que possibilite cursos/treinamentos que repercutem diretamente nos trabalhos práticos e técnicos realizados pelos bibliotecários.

As bibliotecas estão convivendo com usuários mais sofisticados e que possuem exigências diferenciadas, tornando-se importante que o profissional bibliotecário reconheça as expectativas, as motivações e as necessidades diversas tanto de seus clientes reais como dos potenciais.

\section{Habilidades}

Para análise das habilidades do bibliotecário dos 26 itens apresentados, 13 foram classificados em ação e 13 em capacitação. As habilidades distribuíramse nos vários graus indicados, podendo-se identificar os pontos fortes, médios e fracos.

No ponto forte das habilidades, somente um item atingiu os graus excelente e bom e constitui-se em uma habilidade de ação relacionada à capacidade de adaptação a novos métodos de trabalho. Sendo este um ponto positivo, pois dentro da ordem mundial do trabalho e da sociedade do conhecimento, a adaptação a novos métodos de trabalho é considerado um requisito essencial.

As habilidades com pontos médios ou intermediários atingiram os itens de ação e capacitação. (GRÁF. 3).

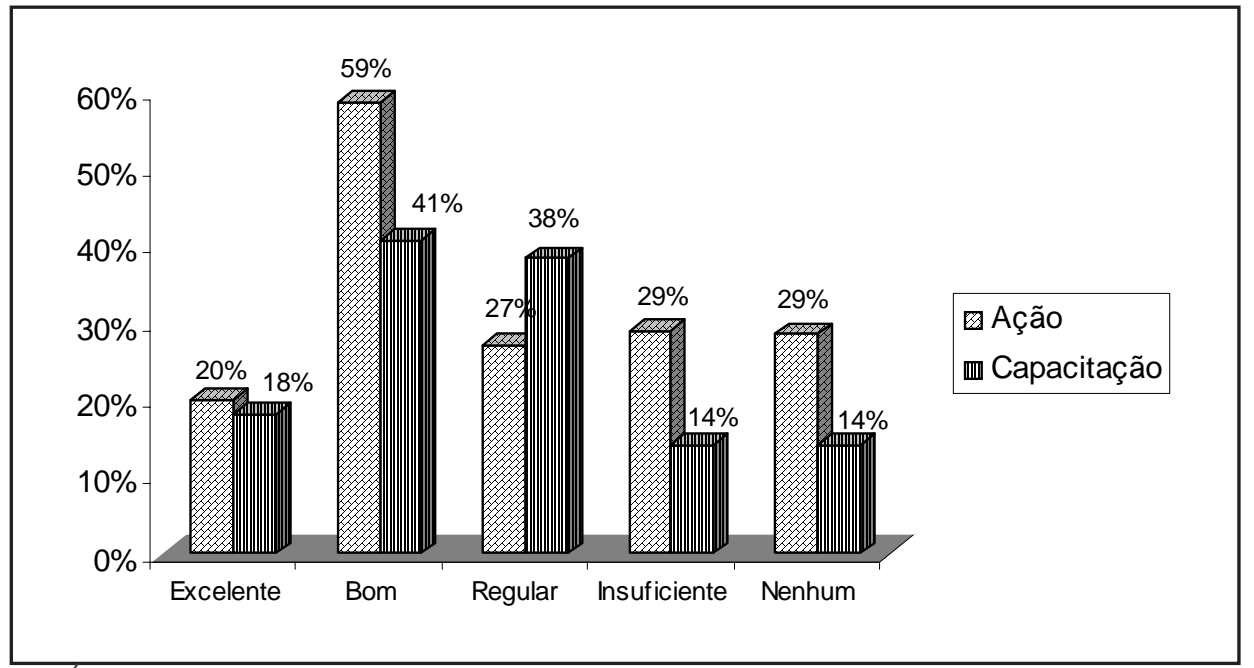

GRÁFICO 3 - Habilidades dos bibliotecários - Pontos médios

Fonte: Dados da pesquisa

Dentre os itens que se classificaram nos pontos médios, tanto de ação quanto de capacitação, em sua maioria, atingiram o grau bom, havendo oscilações entre os outros graus, demonstrando necessidade de rever cada item para melhor capacitar, o que, conseqüentemente, levará à melhoria da ação.

Os pontos fracos envolveram as atividades de ação, cujos graus regular (33\%), insuficiente (33\%) e nenhum (36\%) foram nas atividades de ação que contemplaram a área de marketing, políticas de informação, padrões de qualidade e busca de patrocínios e parcerias. Salienta-se aqui a importância 
da Biblioteca Central formar uma parceria com o Departamento de Administração da Universidade para que os professores, deste departamento, possam ministrar cursos e palavras sobre marketing e outras práticas da administração, para que os serviços e produtos da Biblioteca não estejam sendo subutilizados pela falta de marketing. É primordial que a comunidade universitária tenha conhecimento do que seja uma biblioteca, da sua importância no contexto universitário, e de quais são os produtos e serviços que ela oferece. É imprescindível, ainda, que o usuário tenha confiança e credibilidade nos serviços oferecidos pela biblioteca transformando-a em um propagador de sua importância.

Atitudes

Em relação às atitudes do Bibliotecário, os 24 itens indicados enquadraram-se em graus que os classificaram em pontos fortes e médios, proporcionalmente, não havendo pontos fracos.

As atitudes que envolveram os pontos fortes, foram classificadas em percentuais iguais para os graus excelente e bom (49\%) e envolveram principalmente as relacionadas à qualidade, atendimento ao cliente, aprimoramento, iniciativa e comprometimento com o trabalho. $\bigcirc$ item atendimento com qualidade atingiu 100\% das opiniões no grau excelente, sendo interessante realizar uma pesquisa de opinião junto à comunidade universitária para ouvir sobre o atendimento com qualidade que o profissional bibliotecário de sua instituição vem realizando.

Os itens que se classificaram no ponto médio das atitudes do bibliotecário dividiram-se nos graus excelente (23\%), bom (52\%) e regular (29\%), havendo uma indicação em grau insuficiente.

Dentre as atitudes classificadas nos pontos médios, encontram-se as relacionadas à produtividade, disposição, responsabilidade, trabalho em equipe, participação de eventos, interação com outros profissionais, articulações e posturas políticas. A única atitude que parece como dificuldade maior é o acompanhamento da literatura, não só da área de biblioteconomia/ciência da informação como de áreas correlatas. Vale ressaltar que a Biblioteca Central, além de assinar periódicos da área de Biblioteconomia/Ciência da Informação, tem um expressivo acervo atualizado da área.

\section{Auxiliar de Biblioteca}

\section{Conhecimentos}

Os conhecimentos com pontos fortes do auxiliar de biblioteca abrangeram os serviços administrativos locais, referência e empréstimo.

Os serviços administrativos envolveram a organização, controle, uso e manutenção de mobiliários e equipamentos do ambiente de trabalho. Nos pontos fortes da referência, destacam-se as relações humanas, localização de material e organização do acervo. Sendo as relações humanas (positivas) um fator de sucesso organizacional e individual e também uma forma de desenvolver competências relacionais.

Já para o empréstimo, identificaram-se os principais processos que envolveram esse serviço (empréstimo, devolução, renovação, reserva e cadastro do usuário). 


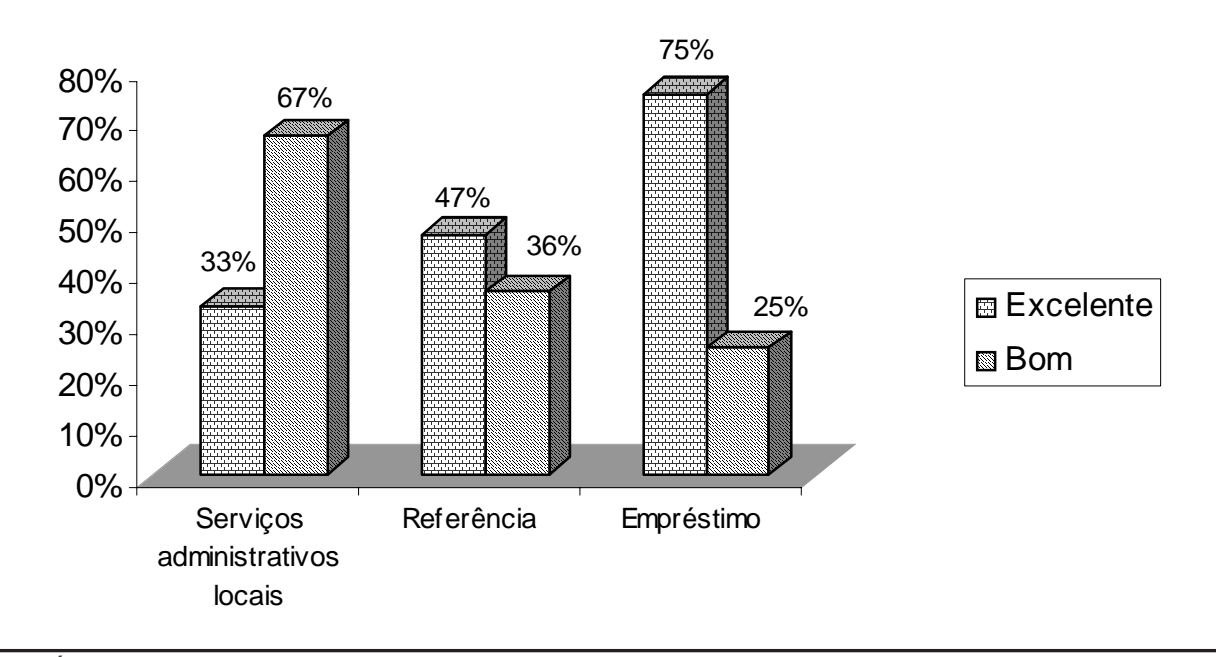

GRÁFICO 4 - Conhecimento do Auxiliar de Biblioteca - Pontos fortes Fonte: Dados da pesquisa

Dentre os graus que classificaram os pontos fortes dos conhecimentos do auxiliar de biblioteca, identifica-se que há oscilações entre os conceitos excelente e bom, concluindo-se que, para alguns, há maior afinidade do que para outros.

As áreas de atuação com pontos médios (GRAF. 5) foram mais variadas, abrangendo serviços administrativos locais, referência, empréstimo, novas tecnologias, aquisição, preservação, processos técnicos e outros serviços administrativos.

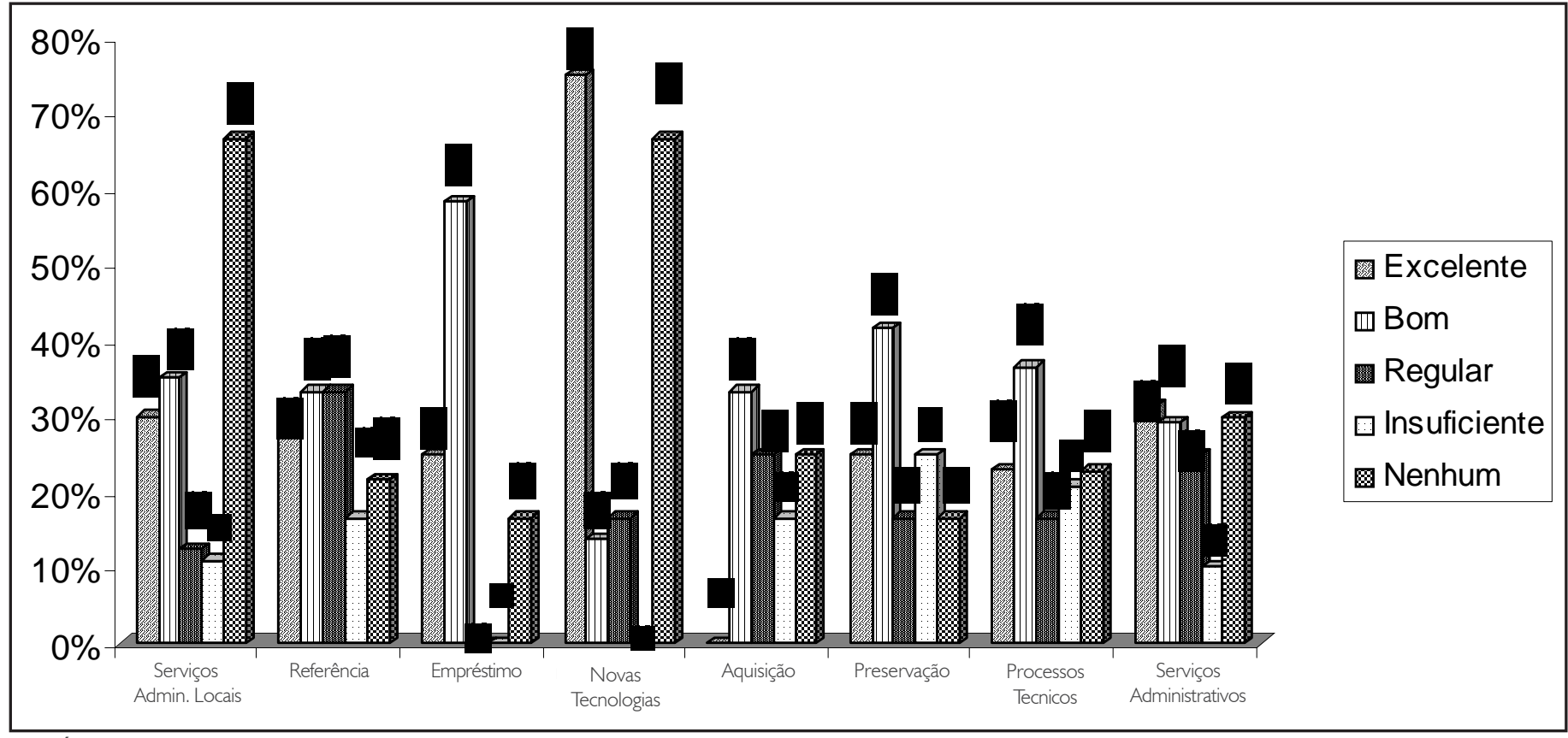

GRÁFICO 5 -Conhecimento do Auxiliar de Biblioteca - Pontos médios

Fonte: Dados da pesquisa

Observa-se que, dependendo da área de atuação, há oscilações mais representativas entre os graus atribuídos do que em outras.

As áreas que apresentaram maior heterogeneidade foram: serviços administrativos locais, empréstimo e novas tecnologias.

Dentre as solicitações realizadas pelos auxiliares de biblioteca para aperfeiçoamento, mencionam-se: Relações humanas; Informática; Qualidade de atendimento ao público. 


\section{Habilidades}

Dentre as 17 habilidades do auxiliar de biblioteca, listadas para atribuição de graus, 7 englobaram as de ação e 10 as de capacitação, as quais foram classificadas entre pontos fortes e intermediários e nenhum item foi classificado como ponto fraco.

Nos pontos fortes, a única habilidade identificada, de ação, foi a de utilizar linguagem acessível ao cliente, que atingiu os graus excelente (33\%) e bom (67\%).

Os pontos médios (GRAF. 6) dividiram-se entre as habilidades de ação e capacitação.

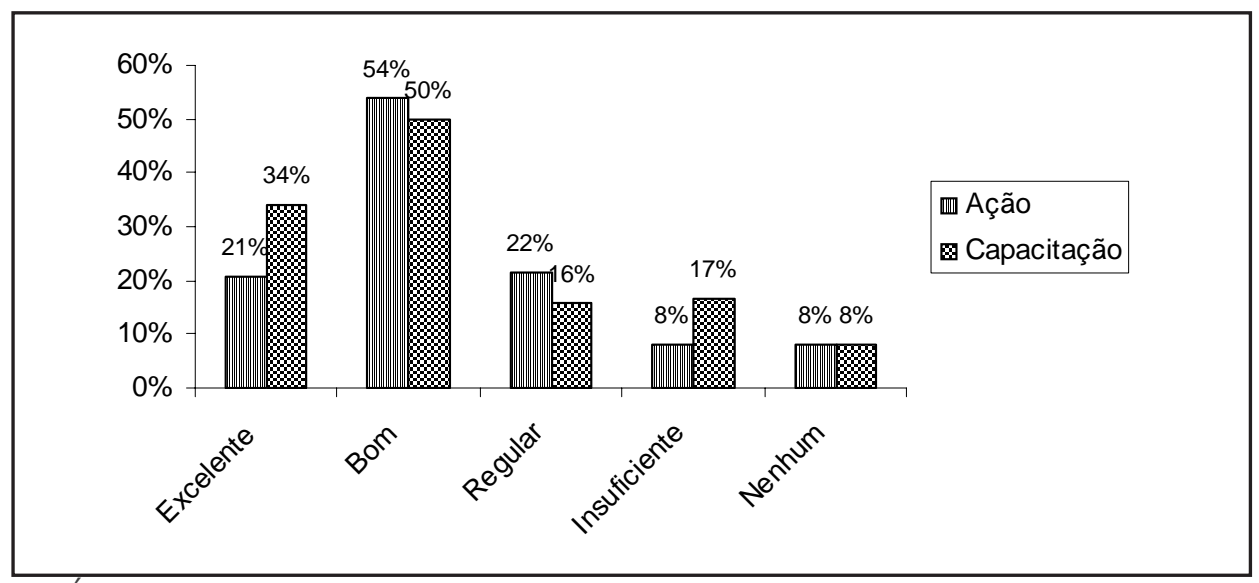

GRÁFICO 6 -Habilidades do Auxiliar de Biblioteca - Pontos médios

Fonte: Dados da pesquisa

Os graus com maior representatividade, atribuídos para as habilidades, foram excelente e bom.

Dentre as habilidades de ação, destacaram-se as relacionadas a identificar os interesses do cliente, operação de computadores, soluções rápidas, argumentação, resolução de problemas e adaptação a novos métodos de trabalho.

As habilidades de capacitação concentram-se nas relações interpessoais, comunicação objetiva, integração, simpatia, administrar stress, trabalhar em equipe e comprometimento com o trabalho.

Atitudes

As atitudes foram relacionadas em 16 itens para atribuição dos graus, onde todas foram classificadas como pontos médios, variando, na maioria, entre os graus excelente e regular com um item com grau nenhum.

Os maiores percentuais das atividades do auxiliar de biblioteca foram para os graus excelente (5I\%) e bom (35\%). Regular apresentou I5\% e nenhum com $8 \%$. As principais atitudes concentram-se em atendimento com qualidade, produtividade, atendimento ao cliente, ética, responsabilidade, comprometimento e atualização.

Os resultados demonstraram ser o segmento auxiliar de biblioteca comprometido com o usuário e, conseqüentemente, com a instituição, fato esse um ponto positivo, pois muitas vezes o funcionário comprometido sem perceber acaba realizando o endomarketing. 


\section{Técnicos de Biblioteca}

\section{Conhecimentos}

A análise dos dados que avaliaram os 57 itens dos conhecimentos do técnico de biblioteca mostraram que estes classificaram-se entre pontos fortes e médios, não se identificando conhecimentos com pontos fracos.

Os pontos fortes (GRÁF. 7) foram representados por 24 itens que abrangeram as áreas de serviços administrativos locais referência, aquisição, processos técnicos e serviços administrativos.

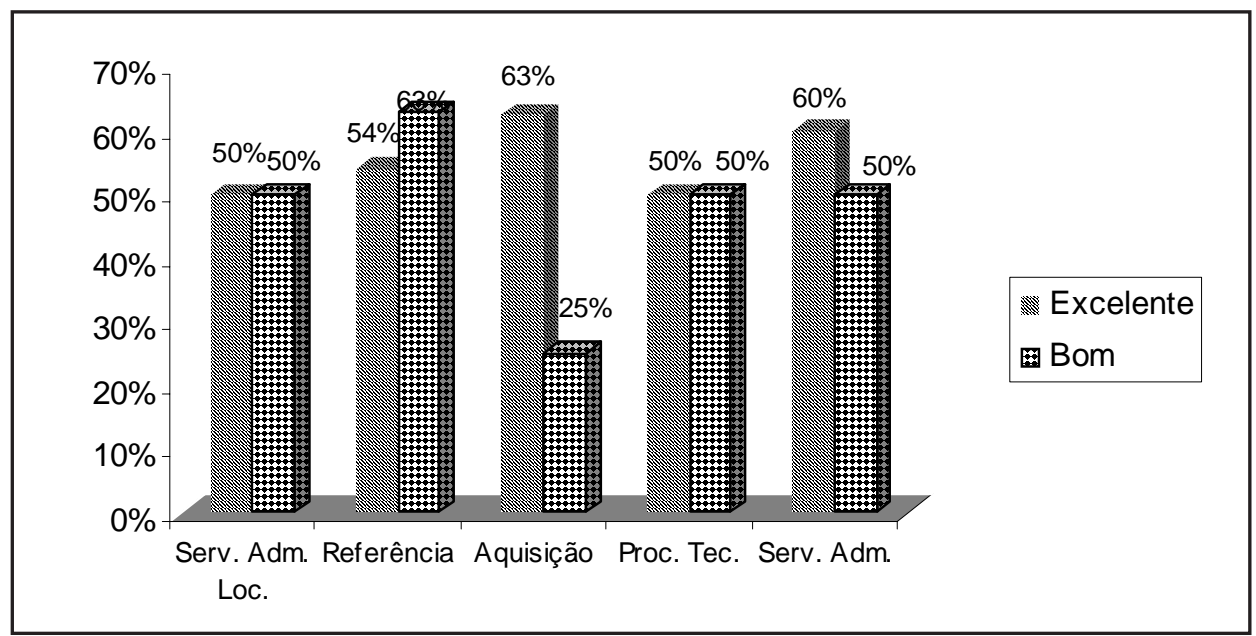

GRÁFICO 7 - Conhecimento do Técnico de Biblioteca - Pontos fortes

Fonte: Dados da pesquisa

Os percentuais dos pontos fortes de conhecimentos do técnico de biblioteca apresentaram percentuais equivalentes e/ou aproximados na maioria das áreas indicadas com oscilação para a área de aquisição.

Os conhecimentos classificados como pontos médios (GRÁF. 8) abrangeram áreas semelhantes dos pontos fortes, incluindo-se ainda empréstimo, novas tecnologias, preservação/restauração que se diferenciaram nos itens assinalados.

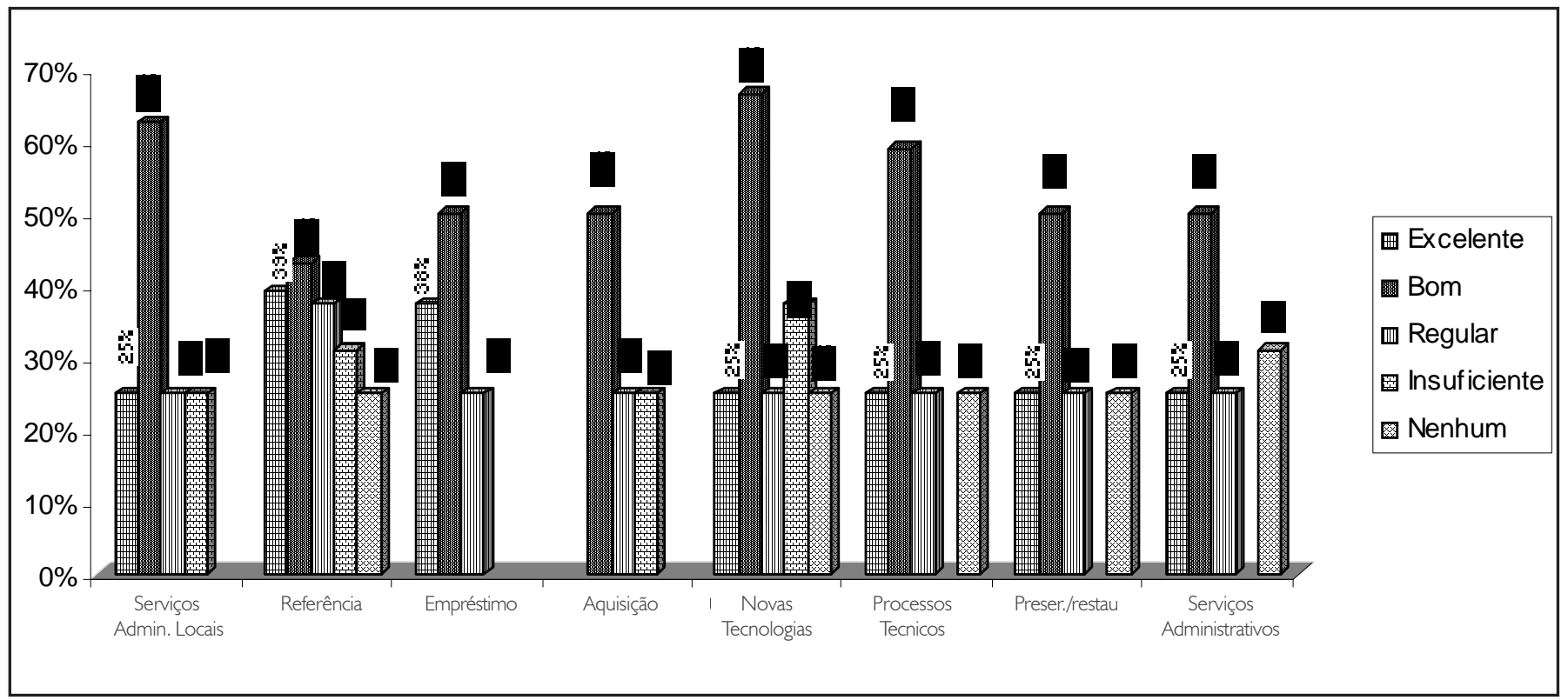

GRÁFICO 8 - Conhecimento do Técnico de Biblioteca - Pontos médios

Fonte: Dados da pesquisa 
Observa-se que, na média, os itens indicados, embora tenham variado entre os conceitos excelente e nenhum, todos apresentaram maior percentual no grau bom.

Os cursos/treinamentos que os técnicos de biblioteca consideraram importantes, são: Informática; Relações humanas; Liderança.

\section{Habilidades}

Foram listadas 17 habilidades para o Técnico de Biblioteca, sendo 7 de ação e 10 de capacitação. As habilidades classificaram-se, em pontos fortes e médios não havendo pontos fracos.

Os pontos fortes foram tanto para as de ação como de capacitação, envolvendo 15 das habilidades indicadas. A ação obteve os graus excelente (25\%) e bom (75\%) e a capacitação com os graus excelente (47\%) e bom (56\%).

As habilidades de ação, com percentuais mais representativos no grau bom, envolveram atendimento ao cliente, operação de equipamentos e resolução de problemas. As habilidades de capacitação abrangeram relações interpessoais, comunicação, integração, percepção, administrar o stress, proatividade, trabalho em equipe e comprometimento.

Duas habilidades foram indicadas como pontos médios, recebendo os graus excelente (25\%), bom (50\%) e regular (25\%).

A capacidade de ação de adaptação a novos métodos de trabalho e argumentação de maneira eficiente foram as habilidades que atingiram os pontos médios, predominando o grau bom e proporcionalmente, em menor escala, o excelente e regular.

\section{Atitudes}

Foram listadas 18 atitudes para o Técnico de Biblioteca, as quais todas se classificaram como pontos fortes deste segmento de sujeitos investigados, representadas pelos graus excelente (54\%) e bom (46\%). Essas atitudes abrangeram os conceitos de qualidade, produtividade, receptividade, atenção ao cliente, responsabilidade, iniciativa, comprometimento, trabalho em equipe e atualização.

\section{Conclusões}

A atuação em áreas diferentes e distintas, muitas vezes exclusivas para determinadas categorias de funcionários, proporciona a oscilação de graus de conhecimento dos três segmentos de servidores analisados neste estudo.

Para o segmento Bibliotecário, os conhecimentos e as habilidades atingiram os pontos fortes, médios e fracos. As atitudes atingiram pontos fortes e médios.

Para o segmento Auxiliar de Biblioteca, os conhecimentos e habilidades atingiram pontos fortes e médios. Já as atitudes foram todas classificadas como pontos médios.

Para o segmento Técnico de Biblioteca, os conhecimentos e habilidades classificaram-se entre pontos fortes e médios. Para as atitudes, todas atingiram pontos fortes. 
Observou-se que o conhecimento, com os itens de acordo com o segmento analisado, é bastante variado em relação à atribuição de grau, dependendo da área de atuação, enquanto que as habilidades e atitudes, com itens semelhantes, variaram de acordo com o segmento analisado.

Desta forma sugere-se que, para estabelecer diretrizes e estratégias de ação, sejam identificados os itens, dentro de cada área, observando-se os percentuais dos dados coletados, para planejamento de treinamentos e programas de capacitação nos itens com maior variação e que atingiram graus insuficiente e nenhum.

Conclui-se, portanto, que, num panorama geral, o segmento Técnico de Biblioteca é preparado e qualificado para executar suas tarefas. O segmento Auxiliar de Biblioteca apresenta maior oscilação de conhecimentos, porém devese considerar ser a categoria mais representativa e que executa tarefas rotineiras.

O segmento Bibliotecário mostrou-se que tem facilidade para adaptarse a novos métodos de trabalho, porém deve realizar cursos de curta duração relacionados a aplicações e novos suportes das tecnologias da informação e comunicação, à administração de recursos informacionais e atividades de conhecimentos específicos, com objetivos definidos contemplando parte teórica e prática para que possa desempenhar com eficiência suas funções, ressaltando as gerenciais já que é este segmento quem planeja, implanta e inova os produtos e serviços nas bibliotecas.

Com isso, a elaboração do mapeamento de competências permitiu identificar as competências necessárias e existentes, bem como os gaps de conhecimentos apresentados pelo staff da Biblioteca.

\section{Mapping of abilities in University Libraries}

This study had the objective of presenting the mapping of competencies of the staff of Prof. Faris Michaele Central Library of Ponta Grossa State University - Parana, Brazil. Thus, the existing positions were listed and the attributions of each of them were identified in order to direct and establish guiding principles. It was verified that Librarians scored strong, average and weak for knowledge and abilities, and strong and average for attitudes. Library assistants scored strong and average for knowledge and abilities, and average for attitudes. Library Technicians scored strong for knowledge and abilities, and average for attitudes.

Key-words: Management of competencies; Professional competency; University library.

\section{REFERENCIAS}

BRANDÃO, H. P.: GUIMARÃESS, T.A. Gestão de competências e gestão de desempenho :tecnologias distintas ou instrumentos de um mesmo construto? RAE: Revista de Administração de Empresas, São Paulo, v. 41, n. 1, p.8.-15, jan./mar. 2001.

DAÓLIO, L. C. O que são competências? Disponivel em: http:///www.tgtreinamento.com.br/artigo9.pdf Acesso em: 10 maio 2004.

DURAND, T. Forms of incompetence. In: INTERNATIONL CONFERENCE ON COMPEETENCE-BASED MANAGEMENT, 4., 1998, Osio. Proceedings . . . Oslo: Norwegian School of Management, 1998. 


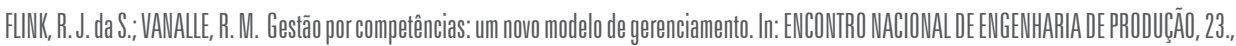
Ouro Preto, Minas Gerais. Anais... Ouro Preto, 2003

PARRY, S.B. Just what is a competency? (and why should you care?) Training Magazine, p. 58-64, June 1998.

ROPÉ, F. ; TANGUYY, L. Introducạ̃o. In: Saberes e competências. o uso de tais noções na escola e na empresa. Campinas: Papirus, 1997. p. 15 -24. TEJADA, J. Fernández. Acerca de las competencias profesionales. Revista Herramientas, Madrid, v. 56, 1999. Disponivel em: http://www.llo.org/public. Acesso em: 10 maio 2001.

uNIVERSIDADE ESTADUAL De PONTA GroSSA. Manual de funçōes. Ponta Grossa: UEPG, 1997.

ZARIFIAN, P.A gestão pela competência. In: SEMINARIO EDUCAÇÃO PROFISSIONAL, TRABALLO E COMPETÊENCIA. [Anais...]. Rio de Janeiro: Centro Internacional para a Educação, Trabalho e Transferência de Tecnologia, 1996.

\section{Anexo A - Conhecimentos \\ Auxiliar de Biblioteca}

Grau: $1=$ excelente $\quad 2=$ bom $\quad 3=$ regular $\quad 4=$ insuficiente $\quad 5=$ nenhum

CONHECIMENTOS

\begin{tabular}{|c|c|c|c|c|}
\hline $\begin{array}{l}\text { I. Conhecer a BICEN (sua estrutura, funcionamento, missão, } \\
\text { políticas e objetivos }\end{array}$ & I & 2 & 3 & 45 \\
\hline 2. Conhecer os produtos e serviços da BICEN & 1 & 2 & 3 & 45 \\
\hline 3. Conhecer as rotinas e processos relativos ao seu trabalho & 1 & 2 & 3 & 45 \\
\hline 4. Controlar as condições de higiene e limpeza do ambiente & I & 2 & 3 & 45 \\
\hline $\begin{array}{l}\text { 5. Organizar, manter a disposição, auxiliar no controle do } \\
\text { uso e manutenção do mobiliário e equipamentos no } \\
\text { ambiente }\end{array}$ & 1 & 2 & 3 & 45 \\
\hline $\begin{array}{l}\text { 6. Preencher planilhas de dados estatísticos e coletar dados } \\
\text { estatisticos }\end{array}$ & 1 & 2 & 3 & 45 \\
\hline 7. Conhecer princípios de relações humanas & 1 & 2 & 3 & 45 \\
\hline $\begin{array}{l}\text { 8. Orientar o usuário sobre o funcionamento, regulamento } \\
\text { e recursos da biblioteca }\end{array}$ & । & 2 & 3 & 45 \\
\hline $\begin{array}{l}\text { 9. Demonstrar capacidade de leitura instrumental de idiomas } \\
\text { estrangeiros }\end{array}$ & । & 2 & 3 & 45 \\
\hline $\begin{array}{l}\text { 10. Elaborar e preparar mural e painel para exposição de } \\
\text { novas aquisições }\end{array}$ & 1 & 2 & 3 & 45 \\
\hline 11. Localizar material no acervo & 1 & 2 & 3 & 45 \\
\hline $\begin{array}{l}\text { 12. Manter o acervo em ordem de acordo com sistema de } \\
\text { classificação adotado }\end{array}$ & । & 2 & 3 & 45 \\
\hline 13. Guardar os documentos/materiais & । & 2 & 3 & 45 \\
\hline 14. Auxiliar na realização de eventos culturais & । & 2 & 3 & 45 \\
\hline 15. Controlar o fluxo do usuário & 1 & 2 & 3 & 45 \\
\hline $\begin{array}{l}\text { 16. Ter domínio das bases do acervo da BICEN (li } \\
\text { periódicos, teses e outras) }\end{array}$ & I & 2 & 3 & 45 \\
\hline
\end{tabular}




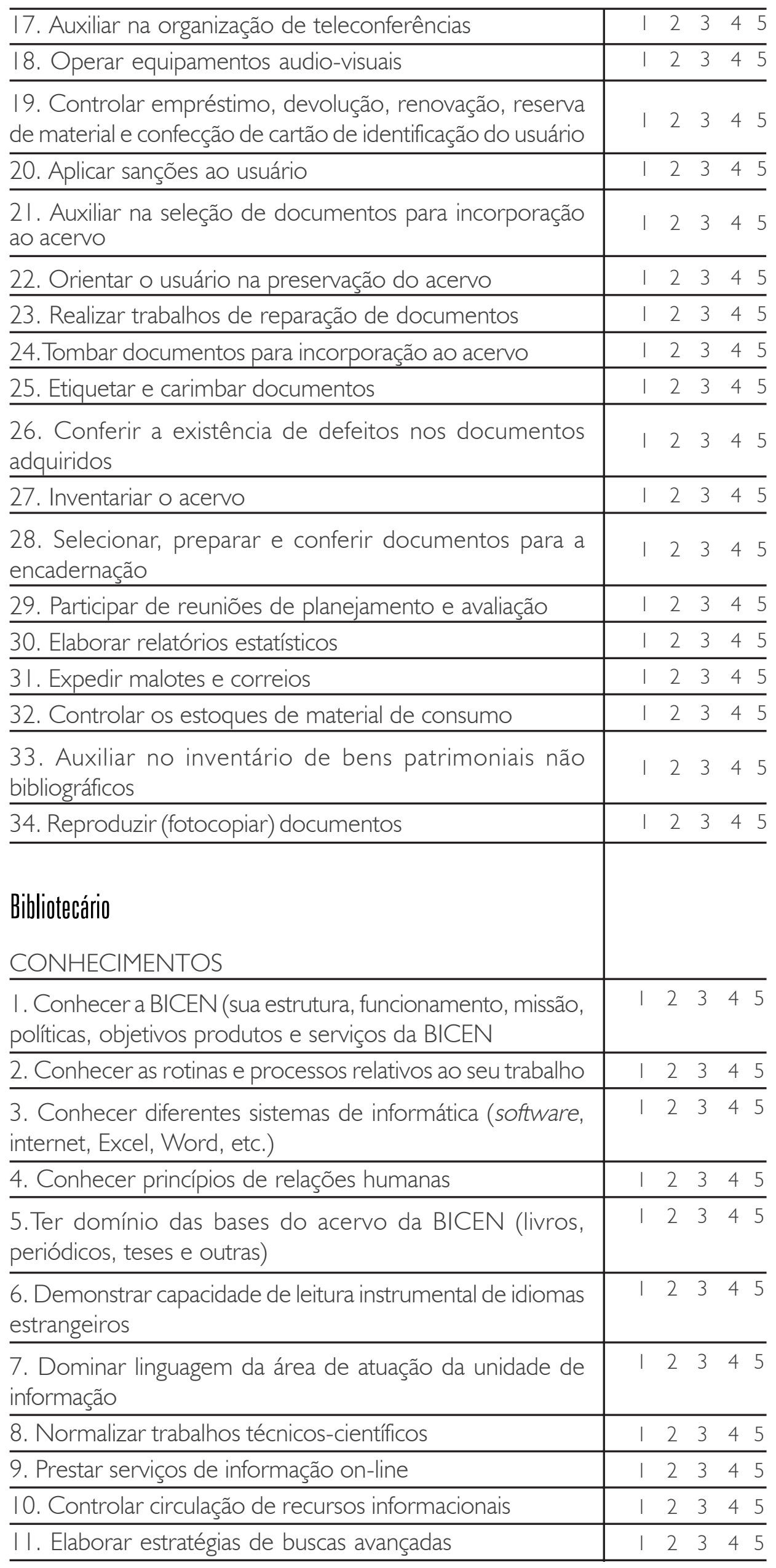




\begin{tabular}{l|lllll}
\hline 45. Capacitar recursos humanos e usuários & 1 & 2 & 3 & 4 & 5 \\
\hline 46. Orientar estágios & 1 & 2 & 3 & 4 & 5 \\
\hline 47. Ministrar palestras & 1 & 2 & 3 & 4 & 5 \\
\hline
\end{tabular}

\section{Técnico de Biblioteca}

\section{CONHECIMENTOS}

I. Conhecer a BICEN (sua estrutura, funcionamento, missão, políticas e objetivos

\begin{tabular}{|c|c|c|c|c|}
\hline 2. Conhecer os produtos e serviços da BICEN & I & 2 & 3 & 45 \\
\hline 3. Conhecer as rotinas e processos relativos ao seu trabalho & 1 & 2 & 3 & 4 \\
\hline 4. Conhecer princípios de relações humanas & I & 2 & 3 & 4 \\
\hline $\begin{array}{l}\text { 5. Ter domínio das bases do acervo da BICEN(livros, } \\
\text { periódicos, teses e outras) }\end{array}$ & I & 2 & & \\
\hline $\begin{array}{l}\text { 6. Demonstrar capacidade de leitura instrumental de idiomas } \\
\text { estrangeiros }\end{array}$ & । & 2 & & \\
\hline
\end{tabular}

7. Orientar o usuário sobre as diversas linguagens para recuperação da informação

\begin{tabular}{l|}
\hline 8. Divulgar materiais promocionais e eventos culturais \\
\hline 9. Elaborar clipping (recortes de jornais) \\
\hline 10. Participar na elaboração de publicações, alertas
\end{tabular}

bibliográficos e manuais de procedimentos

$\frac{\text { 11. Pesquisar por solicitação do usuário }}{\text { 12. Realizar serviços de comutação }}$

e auxiliar na capacitação para uso dos recursos da biblioteca

\begin{tabular}{l|lllll}
\hline 14. Monitorar visitas à biblioteca & $\mid$ & 2 & 3 & 4 & 5 \\
\hline 15. Participar da organização da hemeroteca & 1 & 2 & 3 & 4 & 5 \\
\hline
\end{tabular}

16. Manter o acervo em ordem de acordo com sistema de classificação adotado

17. Apoiar ações da associação de amigos da biblioteca

18. Realizar atividades de leitura em hospitais, presídios e outras instituições

\begin{tabular}{lllll}
1 & 2 & 3 & 4 & 5 \\
\hline & 2 & 3 & 4 & 5
\end{tabular}

19. Elaborar a sinalização do ambiente e avaliar o uso e a adequação do ambiente

20. Preencher planilhas de dados e elaborar dados estatísticos

\begin{tabular}{l|ccccc}
\hline 21. Localizar material no acervo & । & 2 & 3 & 4 & 5 \\
\hline 22. Participar do remanejamento do acervo & । & 2 & 3 & 4 & 5 \\
\hline 23. Controlar o fluxo do usuário & । & 2 & 3 & 4 & 5 \\
\hline $\begin{array}{l}\text { 24. Controlar empréstimo, devolução, renovação e reserva } \\
\text { de material }\end{array}$ & 1 & 2 & 3 & 4 & 5
\end{tabular}




\begin{tabular}{|c|c|c|c|c|}
\hline $\begin{array}{l}\text { 5. Cadastrar e confeccionar o cartão de identificação do } \\
\text { suário }\end{array}$ & I & 2 & & 45 \\
\hline $\begin{array}{l}\text { 26. Auxiliar na aquisição de documentos para incorporação } \\
\text { ao acervo }\end{array}$ & । & 2 & 3 & 45 \\
\hline $\begin{array}{l}\text { 27. Controlar acervo de duplicatas e permutas de } \\
\text { documentos }\end{array}$ & I & 2 & 3 & 45 \\
\hline 8. Realizar campanhas de doação & I & 2 & 3 & 45 \\
\hline $\begin{array}{l}\text { 9. Conhecer diferentes sistemas de informática (software, } \\
\text { ternet, Excel, Word, etc.) }\end{array}$ & 1 & 2 & 3 & 45 \\
\hline 30. Digitalizar materiais & I & 2 & 3 & 45 \\
\hline 1. Operar equipamentos audio-visuais & I & 2 & 3 & 45 \\
\hline 32. Alimentar bases de dados & 1 & 2 & 3 & 45 \\
\hline 33. Auxiliar na operação de sistemas de contratos eletrônicos & I & 2 & 3 & 45 \\
\hline 34. Auxiliar na classificação de documentos & 1 & 2 & 3 & 45 \\
\hline 35. Tombar documentos para incorporação ao acervo & । & 2 & 3 & 45 \\
\hline $\begin{array}{l}\text { 36. Auxiliar na seleção de documentos para incorporação } \\
\text { ao acervo }\end{array}$ & I & 2 & 3 & 45 \\
\hline 37. Etiquetar e carimbar documentos & । & 2 & 3 & 45 \\
\hline $\begin{array}{l}\text { 38. Conferir a existência de defeitos nos documentos } \\
\text { adquiridos }\end{array}$ & 1 & 2 & 3 & 45 \\
\hline 39. Inventariar o acervo & । & 2 & 3 & 45 \\
\hline 40. Auxiliar $n$ & I & 2 & 3 & 45 \\
\hline 41. Realizar trabalhos de reparação de documentos & । & 2 & 3 & 45 \\
\hline 42. Selecionar e preparar documentos para a encadernação & I & 2 & 3 & 45 \\
\hline 43. Participar de reuniões de planejamento e avaliação & I & 2 & 3 & 45 \\
\hline 44. Expedir malotes e correios & I & 2 & 3 & 45 \\
\hline 45. Reproduzir documentos & I & 2 & 3 & 45 \\
\hline 46. Participar & । & 2 & 3 & 45 \\
\hline & । & 2 & 3 & 45 \\
\hline $\begin{array}{l}\text { 47. Colaborar na elaboração do regimento interno da } \\
\text { biblioteca }\end{array}$ & । & 2 & 3 & 45 \\
\hline 48. Auxiliar na elaboração de projetos & 1 & 2 & 3 & 45 \\
\hline 49. Manter cadastro de endereços institucionais & 1 & 2 & 3 & \\
\hline 50. Organizar e controlar arquivos administrativos & 1 & 2 & 3 & 45 \\
\hline $\begin{array}{l}\text { 51. Auxiliar na aquisição de material de consumo, mobiliário, } \\
\text { equipamentos, controlar os estoques de material de } \\
\text { consumo }\end{array}$ & I & 2 & 3 & 45 \\
\hline 52. Executar serviços de digitação e datilografia & I & 2 & 3 & 45 \\
\hline 53. Escrever correspondências & I & 2 & 3 & 45 \\
\hline 54. Participar na elaboração e análise de critérios estatísticos & I & 2 & 3 & 45 \\
\hline 55. Auxiliar na busca de parcerias & 1 & 2 & 3 & 45 \\
\hline $\begin{array}{l}\text { 6. Realizar contatos com lideranças e instituições da } \\
\text { omunidade }\end{array}$ & I & 2 & 3 & \\
\hline
\end{tabular}


57. Auxiliar no controle do uso, manutenção dos equipamentos e controlar a disposição do mobiliário, $\begin{array}{llll}2 & 3 & 4 & 5\end{array}$ equipamentos higiene e limpeza do ambiente

\section{ANEXO B - HABILLDADES}

\section{Bibliotecário}

HABILIDADES

\begin{tabular}{|c|c|c|c|c|}
\hline $\begin{array}{l}\text { I. Identificar as características e expectativas do cliente em } \\
\text { relação a BICEN }\end{array}$ & I & 2 & 3 & 45 \\
\hline 2. Utilizar uma linguagem acessível ao cliente & I & 2 & 3 & 45 \\
\hline 3. Produzir soluções rapidamente (demonstrar agilidade) & । & 2 & 3 & 45 \\
\hline $\begin{array}{l}\text { 4. Operar computadores, periféricos e outros recursos } \\
\text { tecnológicos }\end{array}$ & । & 2 & 3 & 45 \\
\hline $\begin{array}{l}\text { 5. Argumentar de maneira convincente (saber sustentar seus } \\
\text { argumentos sobre produtos e serviços da BICEN) }\end{array}$ & । & 2 & 3 & 45 \\
\hline $\begin{array}{l}\text { 6. Demonstrar capacidade de adaptação a novos métodos } \\
\text { de trabalho }\end{array}$ & । & 2 & 3 & 45 \\
\hline 7. Resolver problemas não comuns no seu dia-a-dia & । & 2 & 3 & 45 \\
\hline 8. Desenvolver planos de divulgação e marketing & । & 2 & 3 & 45 \\
\hline 9. Desenvolver políticas de informação & I & 2 & 3 & 45 \\
\hline I0. Desenvolver padrões de qualidade gerencial & I & 2 & 3 & 45 \\
\hline 1 I. Controlar a execução dos planos de atividades & I & 2 & 3 & 45 \\
\hline 12. Buscar patrocínios e parcerias & I & 2 & 3 & 45 \\
\hline 13. Elaborar manuais de serviços e procedimentos & । & 2 & 3 & 45 \\
\hline 14. Conquistar a simpatia e o apreço do cliente & । & 2 & 3 & 45 \\
\hline $\begin{array}{l}\text { 15. Observar e perceber os fatos que o cercam e suas } \\
\text { conseqüências (ser perspicaz) }\end{array}$ & । & 2 & 3 & 45 \\
\hline 16. Trabalhar sob pressão, administrando o stress & । & 2 & 3 & 45 \\
\hline 17. Ser proativo (visão antecipada) & । & 2 & 3 & 45 \\
\hline 18. Demonstrar capacidade de comunicação oral e escrita & । & 2 & 3 & 45 \\
\hline 19. Liderar equipes & I & 2 & 3 & 45 \\
\hline 20. Trabalhar em equipe e em rede & । & 2 & 3 & 45 \\
\hline 21. Demonstrar capacidade de análise e síntese & I & 2 & 3 & 45 \\
\hline 22. Demonstrar capacidade de negociação & । & 2 & 3 & 45 \\
\hline 23. Demonstrar senso de organização & । & 2 & 3 & 45 \\
\hline 24. Demonstrar capacidade empreendedora & । & 2 & 3 & 45 \\
\hline 25. Demonstrar raciocínio lógico & I & 2 & 3 & 45 \\
\hline 26. Demonstrar capacidade de concentração & । & 2 & 3 & 45 \\
\hline
\end{tabular}




\section{Auxiliar e Técnico de Biblioteca}

\begin{tabular}{|c|c|c|c|c|}
\hline $\begin{array}{l}\text { I. Identificar as características e expectativas do cliente em } \\
\text { relação a BICEN }\end{array}$ & I & 2 & 3 & 4 \\
\hline 2. Utilizar uma linguagem acessível ao cliente & । & 2 & 3 & 45 \\
\hline $\begin{array}{l}\text { 3. Operar computadores, periféricos e outros recursos } \\
\text { tecnológicos }\end{array}$ & I & 2 & 3 & 4 \\
\hline 4. Produzir soluções rapidamente (demonstrar agilidade) & । & 2 & 3 & 45 \\
\hline $\begin{array}{l}\text { 5. Argumentar de maneira convincente (sustentar seus } \\
\text { argumentos sobre produtos e serviços da BICEN) }\end{array}$ & I & 2 & 3 & 4 \\
\hline 6. Resolver problemas não comuns no seu dia-a-dia & I & 2 & 3 & 4 \\
\hline $\begin{array}{l}\text { 7. Demonstrar capacidade de adaptação a novos métodos } \\
\text { de trabalho }\end{array}$ & I & 2 & 3 & 45 \\
\hline 8. Manter boas relações interpessoais com clientes e colegas & । & 2 & 3 & 4 \\
\hline 9. Comunicar-se com clareza e objetividade & । & 2 & 3 & $4: 5$ \\
\hline 10. Buscar as informações de que necessita para o trabalho & । & 2 & 3 & 4 \\
\hline $\begin{array}{l}\text { II. Integrar-se a diferentes contextos sociais (relacionar-se } \\
\text { com diferentes pessoas, culturas, situações, etc) }\end{array}$ & । & 2 & 3 & 4 \\
\hline 12. Conquistar a simpatia e o apreço do cliente & । & 2 & 3 & 4 \\
\hline $\begin{array}{l}\text { 13. Observar e perceber os fatos que o cercam e suas } \\
\text { conseqüências (ser perspicaz) }\end{array}$ & I & 2 & 3 & \\
\hline 14. Trabalhar sob pressão, administrando o stress & I & 2 & 3 & 4 \\
\hline 15. Ser proativo (visão antecipada) & । & 2 & 3 & 4 \\
\hline 16. Trabalhar em equipe & । & 2 & 3 & 4 \\
\hline 17. Demonstrar comprometimento com o trabalho & 1 & 2 & 3 & 4 \\
\hline
\end{tabular}

\section{ANEXO C - AIITUDES}

Bibliotecário

ATITUDES

\begin{tabular}{|c|c|c|c|c|}
\hline $\begin{array}{l}\text { I. Reconhecer a importância de prestar um atendimento } \\
\text { de qualidade }\end{array}$ & । & 2 & 3 & 45 \\
\hline 2. Demonstrar produtividade & । & 2 & 3 & 45 \\
\hline $\begin{array}{l}\text { 3. Demonstrar receptividade ao cliente (manifestar satisfação, } \\
\text { disponibilidade e interesse em atender o cliente) }\end{array}$ & । & 2 & 3 & 45 \\
\hline $\begin{array}{l}\text { 4. Demonstrar empatia ao cliente (saber colocar-se no lugar } \\
\text { do cliente) }\end{array}$ & । & 2 & 3 & 4 \\
\hline 5. Demonstrar cortesia e educação & । & 2 & 3 & 45 \\
\hline 6. Reconhecer a importância do cliente para a BICEN & । & 2 & 3 & 45 \\
\hline $\begin{array}{l}\text { 7. Demonstrar sensibilidade em relação aos problemas e } \\
\text { dificuldades do cliente }\end{array}$ & । & 2 & & 4 \\
\hline
\end{tabular}


8. Demonstrar disposição para reposicionar-se em razão de mudanças nos desejos dos cliente, nos objetivos da

BICEN (ser flexível)

9. Dispensar igualdade de tratamento aos clientes (reconhecer igualmente o direito de cada cliente, sem discriminação)

I0. Demonstrar paciência (ser tolerante e estar disposto a ouvir o cliente)

II. Ser ético na relação com os clientes (reconhecer e valorizar a conduta correta)

12. Assumir a responsabilidade frente a situações de trabalho para responder a contendo às demandas do cliente e da BICEN

13. Manifestar o desejo de aprender continuamente e aprimorar-se profissionalmente

\begin{tabular}{|c|c|c|c|c|c|}
\hline 14. Respeitar a privacidade do cliente & । & 2 & & & \\
\hline 15. Demonstrar iniciativa & । & 2 & 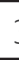 & & \\
\hline 16. Demonstrar comprometimento com o trabalho & । & 2 & & & \\
\hline 17. Trabalhar em equipe & । & 2 & & & \\
\hline $\begin{array}{l}\text { 18. Divulgar com maior transparência a profissão no âmbito } \\
\text { da sociedade }\end{array}$ & । & 2 & & & \\
\hline 19. Participar de eventos da área & । & 2 & & & \\
\hline 20. Interagir com profissionais de áreas correlatas & । & 2 & & & \\
\hline 21. Articular e contextualizar informações & । & 2 & & & \\
\hline 22. Ter postura política e gerencial na área de informação & । & 2 & & & \\
\hline 23. Aplicar seus conhecimentos de forma crítica e objetiva & । & 2 & & & \\
\hline $\begin{array}{l}\text { 24. Entender e acompanhar a literatura sobre a } \\
\text { Biblioteconomia, Ciência da Informação e áreas correlatas }\end{array}$ & । & 2 & & & \\
\hline
\end{tabular}

\section{Auxiliar e Técnico de Biblioteca}

\section{ATITUDES}

\begin{tabular}{|c|c|c|c|c|}
\hline $\begin{array}{l}\text { 1. Reconhecer a importância de prestar um atendimento } \\
\text { de qualidade }\end{array}$ & I & 2 & 3 & 45 \\
\hline 2. Demonstrar produtividade & । & 2 & 3 & 45 \\
\hline $\begin{array}{l}\text { 3. Demonstrar receptividade ao cliente (manifestar satisfação, } \\
\text { disponibilidade e interesse em atender o cliente) }\end{array}$ & । & 2 & 3 & 45 \\
\hline $\begin{array}{l}\text { 4. Demonstrar empatia ao cliente (saber colocar-se no lugar } \\
\text { do cliente) }\end{array}$ & I & 2 & 3 & 45 \\
\hline 5. Demonstrar cortesia e educação & I & 2 & 3 & 45 \\
\hline 6. Reconhecer a importância do cliente para a BICEN & 1 & 2 & 3 & 45 \\
\hline $\begin{array}{l}\text { 7. Demonstrar sensibilidade em relação aos problemas e } \\
\text { dificuldades do cliente }\end{array}$ & I & 2 & 3 & 45 \\
\hline
\end{tabular}


8. Demonstrar disposição para reposicionar-se em razão de mudanças nos desejos dos cliente, nos objetivos da $1 \quad 2345$ BICEN (ser flexível)

9. Dispensar igualdade de tratamento aos clientes (reconhecer igualmente o direito de cada cliente, sem 12345 discriminação)

10. Demonstrar paciência (ser tolerante e estar disposto a ouvir o cliente)

II. Ser ético na relação com os clientes (reconhecer e valorizar a conduta correta)

12. Assumir a responsabilidade frente a situações de trabalho para responder a contento às demandas do cliente e da BICEN

13. Manifestar o desejo de aprender continuamente e aprimorar-se profissionalmente

\begin{tabular}{l|lllll}
\hline 14. Respeitar a privacidade do cliente & 1 & 2 & 3 & 4 & 5 \\
\hline 15. Demonstrar comprometimento com o trabalho & 1 & 2 & 3 & 4 & 5 \\
\hline 16. Manter-se atualizado & 1 & 2 & 3 & 4 & 5 \\
\hline
\end{tabular}

